\title{
Pembuatan Klem Pemegang Pipa Paralon dari Limbah Plastik Menggunakan Proses Compression molding
}

\author{
Suyadi, Ariawan Wahyu Pratomo, Paryono, Poedji Haryanto, Mochamad Denny Surindra* \\ Jurusan Teknik Mesin, Politeknik Negeri Semarang \\ Jl. Prof. H. Soedarto, S.H., Tembalang, Semarang \\ *Email: dennysurindra@yahoo.com.sg
}

\begin{abstract}
Abstrak
Tujuan penelitian ini adalah menaikkan nilai tambah sampah plastik menjadi produk klem pemegang pipa paralon dengan proses compression molding di bengkel teknik mesin Polteknik negeri Semarang. Sampah plastik yang sering kita jumpai disekitar kita adalah jenis Polyethylene Terephthalate (PET) dari bekas kemasan air mineral dan Polypropylene (PP) dari bekas alat rumah tangga seperti ember, kursi dan lain-lainya, agar mengurangi beban lingkungan maka perlu di daur ulang menjadi produk klem pemegang pipa paralon dengan proses compression molding, dari hasil penelitian diperoleh kekuatan tegangan bengkok produk klem plastik penjepit paralon yaitu bahan plastik daur ulang PP menghasilkan kekuatan/tegangan bengkok sebesar $\sigma_{b}=4,67 \mathrm{~N} / \mathrm{mm}^{2}$, dan bahan plastik daur ulang PET menghasilkan kekuatan/tegangan bengkok sebesar $\sigma_{b}=4,325 \mathrm{~N} / \mathrm{mm}^{2}$.
\end{abstract}

Diterima: 12-08-2020; Direvisi: 21-08-2020; Dipublikasi: 28-12-2020

Kata kunci: Sampah; Plastik; Klem; Pipa paralon; Compression molding

\begin{abstract}
The purpose of this research is to increase the added value of plastic waste into clamp products for pipe holder using compression molding process in the mechanical engineering workshop of the State Polytechnic of Semarang. Plastic waste that we often encounter around us is the type of Polyethylene Terephthalate (PET) from used mineral water packaging and polypropylene (PP) from used household appliances such as buckets, chairs and others, in order to reduce the environmental burden, it needs to be recycled into pipe clamp products with a compression molding process, from the research results obtained the bending stress strength of the plastic clamp paralon clamp product, namely recycled plastic $P P$ which produces bending strength / stress of $\sigma_{b}=4,67 \mathrm{~N} / \mathrm{mm}^{2}$, and the recycled plastic material PET produces bending strength / stress of $\sigma_{b}=4,325 \mathrm{~N} / \mathrm{mm}^{2}$.
\end{abstract}

Keywords: Trash; Plastic; clamp; pipe paralon; Compression molding

\section{Pendahuluan}

Harus diakui bahwa plastik memang memiliki harga yang relatif murah dibandingkan dengan bahan yang lain sehingga siapapun yang menginginkannya pasti dapat membelinya dengan mudah, tetapi ketika dibuang ke lokasi TPA, plastik justru tidak dapat terurai dengan cepat dan mudah, sehingga hal itu dapat dengan mudahnya mencemari tanah di daerah tersebut. Pencemaran tanah inilah yang kemudian berdampak buruk terhadap lingkungan.

Limbah plastik dipandang sebagai masalah yang lebih serius dibandingkan dengan limbah organik karena sifat-sifat khusus yang dimilikinya, yaitu tidak bisa terurai secara alami (non-biodegradable), tidak menyerap air dan juga tidak dapat berkarat. Karena sifatnya tersebut limbah plastik bisa menimbulkan banyak efek negatif terhadap alam seperti pembentukan film/kantongan yang dapat menyumbat aliran air di parit, selokan, sungai ataupun tempat terbuka yang dapat mengakibatkan genangan air dan tidak jarang bisa menimbulkan banjir, selain itu dapat merusak stabilitas ekosistem, lain halnya dengan limbah organik yang bisa terurai di alam dengan sendirinya.

Salah satu cara penanganan limbah plastik adalah dengan mendaur ulang [1], seperti pada penelitian ini yaitu sampah plastik dipilih yang bisa didaur ulang seperti PET (polietheline teraphalet) [2] dari bekas wadah kemasaan air mineral dan PP (poliprophilien) dari bekas loyang, kursi atau alat rumah tangga yang lain, kedua jenis plastik ini yang paling banyak kita jumpai dan bisa didaur ulang [3]. Pada penelitian ini akan dilakukan daur ulang limbah plastik dari 
Suyadi dkk./Jurnal Rekayasa Mesin

p-ISSN: 1411-6863, e-ISSN: 2540-7678

Vol.15|No.3|220-228|Desember|2020

bahan PET dan PP untuk dijadikan suatu produk klem pemegang pipa paralon dengan cara compression molding dengan tujuan mengurangi beban lingkungan dan meningkatkan nilai tambah limbah plastik menjadi benda yang bermanfaat.

Adapun tujuan penelitian ini adalah merancang dan membuat alat cetak plastik jenis compression molding, menaikan nilai tambah limbah plastik yang tidak bernilai menjadi produk bernilai ekonomi, dan mengurangi beban lingkungan dari limbah/sampah plastik.

\section{Metode Penelitian}

Tahapan penelitian dan semua rangkaian kegiatan akan kami lakukan di Laboratorium Teknik Mesin Politeknik Negeri Semarang. Adapun tahapan penelitian ini sebagai berikut seperti diagram alir pada Gambar 1.

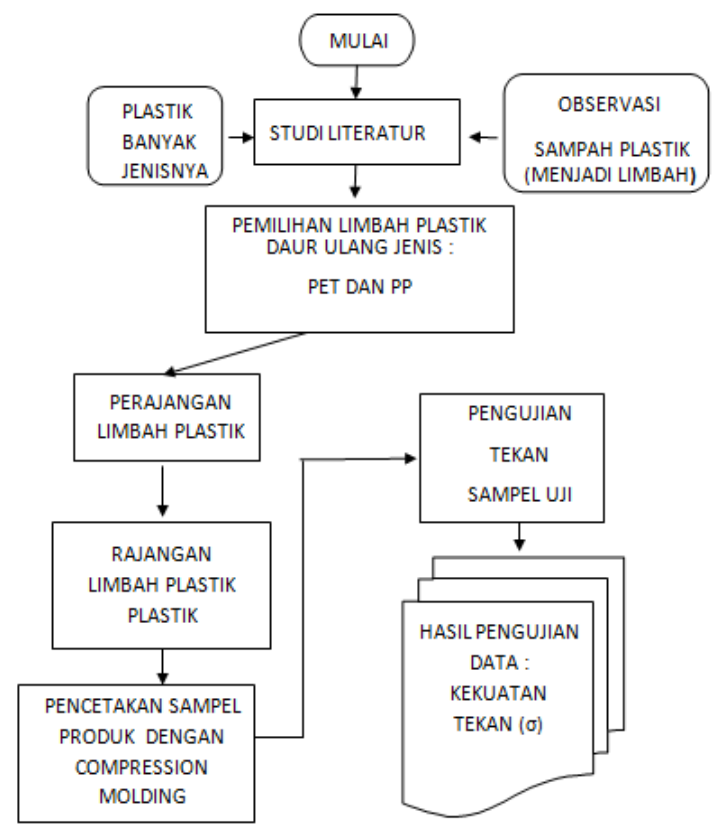

Gambar 1. Diagram Alir Penelitian

\section{Hasil dan Pembahasan}

\subsection{Hasil Rancang Bangun Cetakan Produk}

Bahan cetakan (dies) produk dari baja karbon yang mampu menerima panas sampai $250^{\circ} \mathrm{C}$ dan mampu menahan gaya tekan 5000 N. Cetakan terbagi dua yaitu cetakan atas dan cetakan bawah masing-masing mempunyai ukuran tebal $18 \mathrm{~mm}$ x $60 \mathrm{~mm}$ x $100 \mathrm{~mm}$ seperti Gambar 2 dan kalau cetakan atas dan bawah ditangkupkan menjadi ukuran $18 \mathrm{~mm}$ x $90 \mathrm{~mm}$ x $100 \mathrm{~mm}$, seperti pada Gambar 3.

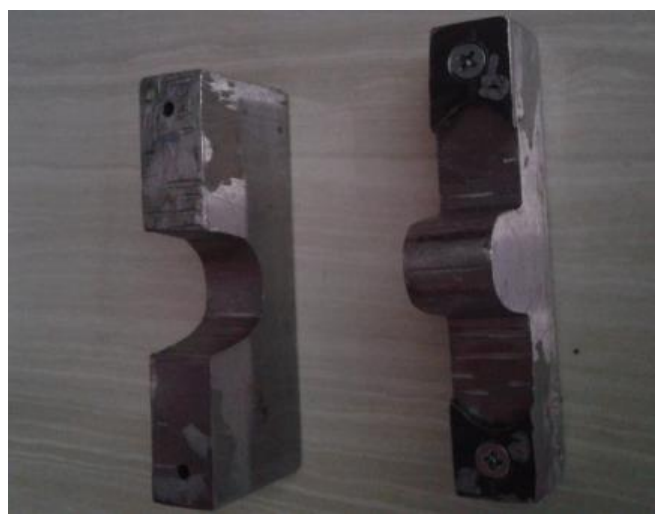

Gambar 2. Cetakan atas dan bawah 
Suyadi dkk./Jurnal Rekayasa Mesin p-ISSN: 1411-6863, e-ISSN: 2540-7678

Vol.15|No.3|220-228|Desember|2020

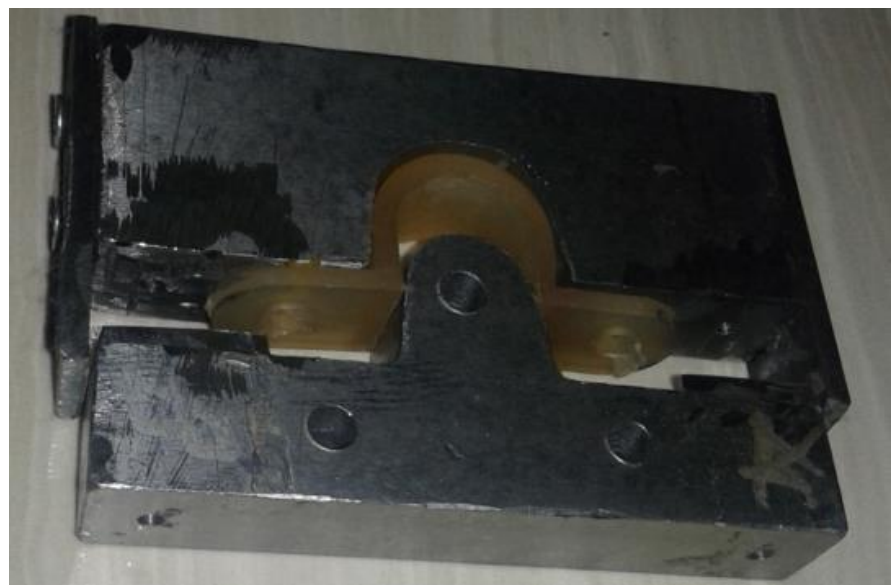

Gambar 3. Cetakan atas dan bawah saat ditangkupkan

\subsection{Produk Hasil Pencetakan}

Produk hasil pencetakan penelitian berupa klem penjepit pipa paralon $1 / 2$ inchi dari bahan baku limbah plastik Polypropylene (PP) dan Polyethylene Terephthalate (PET) yang didaur ulang dengan proses perajangan dengan ukuran 3 x $3 \mathrm{~mm}$ kemudian dipanaskan sampai suhu $225^{\circ} \mathrm{C}$ bahan PP dan $250^{\circ} \mathrm{C}$ untuk bahan PET setelah itu dimasukkan dalam cetakan dan di press dengan gaya tekan $5000 \mathrm{~N}$.

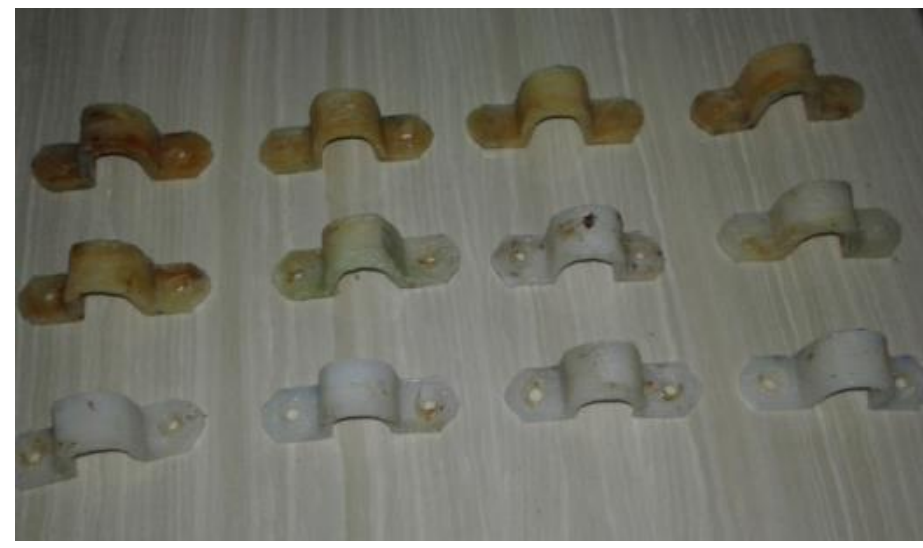

Gambar 4. Produk hasil pencetakan dari bahan PET

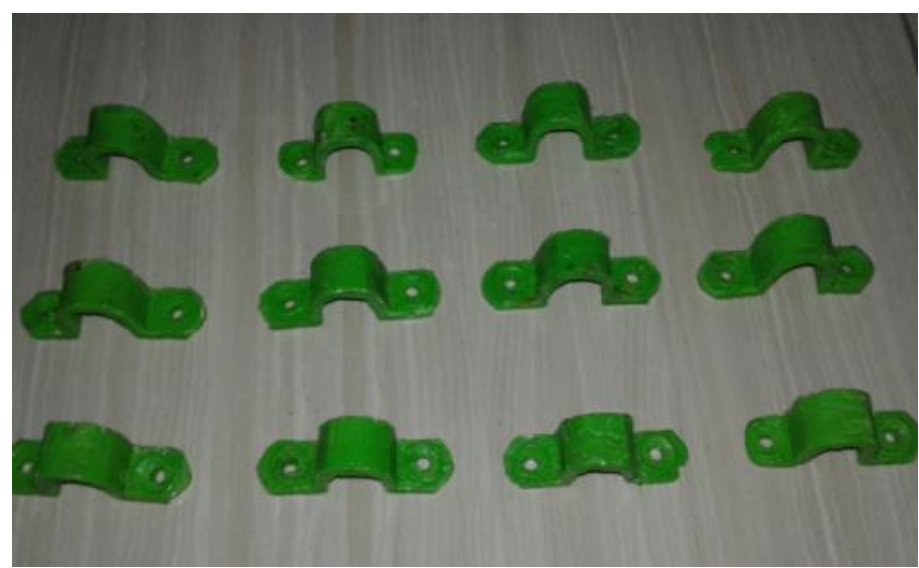

Gambar 5. Produk hasil pencetakan dari bahan PP 
Suyadi dkk./Jurnal Rekayasa Mesin

p-ISSN: 1411-6863, e-ISSN: 2540-7678

Vol.15|No.3|220-228|Desember|2020

\subsection{Pengujian Tekan Produk Hasil Pencetakan}

Pengujian kekuatan produk dilakukan dengan uji tekan sampai produk menjadi retak atau sampai pecah [4-7]. Mekanisme pembebanan dapat dilihat pada Gambar 6.

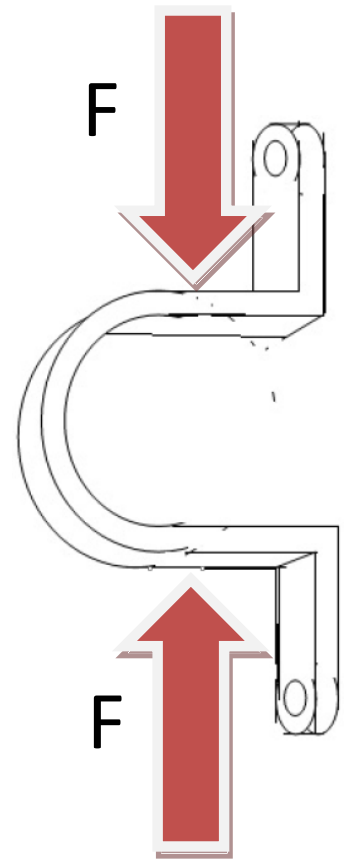

Gambar 6. Produk hasil pencetakan diuji tekan

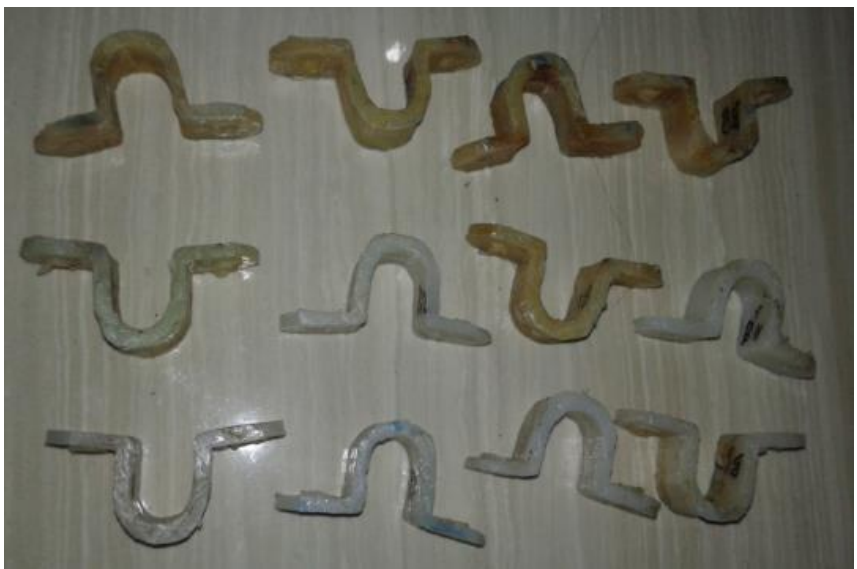

Gambar 7. Produk bahan PET setelah mengalami uji tekan sampai retak atau pecah

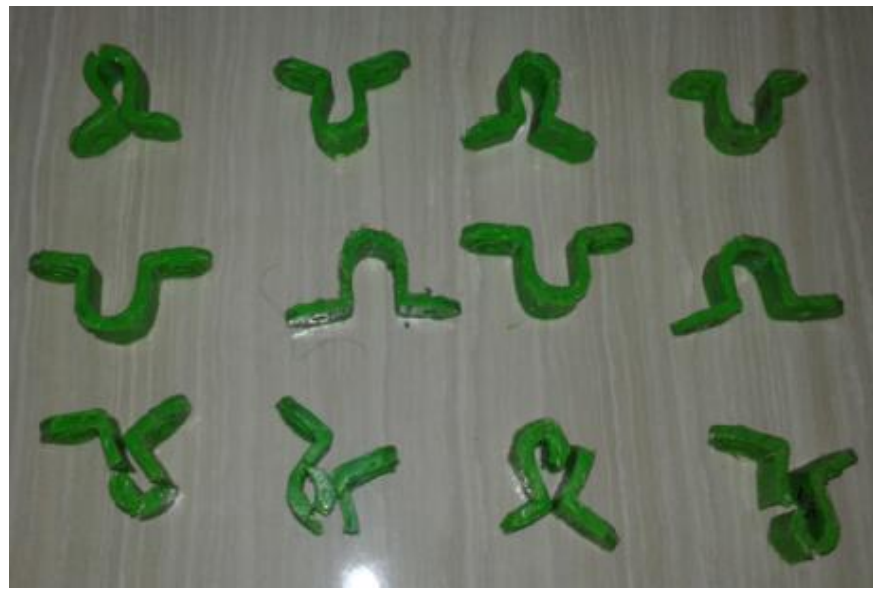

Gambar 8. Produk bahan PP setelah mengalami uji tekan sampai retak atau pecah 
Suyadi dkk./Jurnal Rekayasa Mesin p-ISSN: 1411-6863, e-ISSN: 2540-7678

Vol.15|No.3|220-228|Desember|2020

Pengujian tekan merupakan tahapan penelitian yang diperlukan agar dapat mengetahui kekuatanya seperti gaya tekan $(F)$, momen bengkok $\left(M_{b}\right)$, momen tahanan bengkok $\left(W_{b}\right)$, dan tegangan bengkok $\left(\sigma_{b}\right)$.

Tabel 1. Data hasil Pengujian Tekan bahan Polypropylene (PP)

\begin{tabular}{|c|c|c|c|c|c|c|}
\hline No. & Kode & $\mathbf{F}(\mathbf{N})$ & $\mathbf{M}_{\mathrm{b}}(\mathrm{Nmm})$ & $\mathrm{Wb}\left(\mathrm{mm}^{3}\right)$ & $\sigma_{b}\left(N / m^{2}\right)$ & Keterangan \\
\hline 1 & A1 & 271,1 & 2982,6 & 900 & 3,3 & \\
\hline 2 & $\mathrm{~A} 2$ & 203,4 & 2237 & 900 & 5,1 & \\
\hline 3 & A3 & 237,3 & 2609,8 & 576 & 4,5 & \\
\hline 4 & A4 & 237,3 & 2609,8 & 576 & 4,5 & \\
\hline 5 & A5 & 203,4 & 2237 & 576 & 3,9 & \\
\hline 6 & A6 & 237,3 & 2610 & 729 & 5,9 & \\
\hline 7 & A7 & 339 & 3728,3 & 729 & 4,1 & \\
\hline 8 & A8 & 339 & 3728,3 & 441 & 5,1 & \\
\hline 9 & A9 & 305 & 3355,5 & 576 & 4,6 & \\
\hline 10 & A10 & 271,1 & 2982,6 & 441 & 5,2 & \\
\hline 11 & A11 & 339 & 3728,3 & 576 & 6,5 & \\
\hline \multirow[t]{2}{*}{12} & A12 & 271,1 & 2982,6 & 900 & 3,3 & \\
\hline & Rerata & 271,1667 & 2982,65 & 660 & 4,666667 & \\
\hline
\end{tabular}

Tabel 2. Data hasil Pengujian Tekan bahan Polyethylene Terephthalate (PET)

\begin{tabular}{|c|c|c|c|c|c|c|}
\hline No. & Kode & $\mathbf{F}(\mathbf{N})$ & $\mathbf{M}_{b}(\mathrm{Nmm})$ & $\mathrm{Wb}\left(\mathbf{m m}^{3}\right)$ & $\sigma_{b}\left(N / m^{2}\right)$ & Keterangan \\
\hline 1 & B1 & 203,4 & 2237 & 576 & 3,9 & \\
\hline 2 & B2 & 203,4 & 2237 & 576 & 3,9 & \\
\hline 3 & B3 & 203,4 & 2237 & 576 & 3,9 & \\
\hline 4 & B4 & 203,4 & 2237 & 576 & 3,9 & \\
\hline 5 & B5 & 203,4 & 2237 & 576 & 3,9 & \\
\hline 6 & B6 & 203,4 & 2237 & 441 & 3,9 & \\
\hline 7 & B7 & 203,4 & 2237 & 576 & 5,1 & \\
\hline 8 & B8 & 237,3 & 2610 & 441 & 5,9 & \\
\hline 9 & B9 & 203,4 & 2237 & 576 & 3,9 & \\
\hline 10 & B10 & 237,4 & 2610 & 576 & 4,5 & \\
\hline 11 & B11 & 271,1 & 2983 & 576 & 5,2 & \\
\hline 12 & $\mathrm{~B} 12$ & 203,4 & 2237 & 576 & 3,9 & \\
\hline Rerata & & 214,7 & 2361,333 & 553,5 & 4,325 & \\
\hline
\end{tabular}

3.4. Pembahasan Data Hasil Pengujian Tekan Sampel Uji Polypropylene (PP)

3.4.1. Gaya Bengkok pada hasil Pengujian Kekuatan sampel uji berbahan PP

Berdasarkan hasil pengujian beban bengkok seperti Gambar 9, keduabelas sampel uji berbahan plastik PP daur ulang menunjukkan kekuatan bengkok terendah 203,4 N dan yang tertinggi $339 \mathrm{~N}$ dan kekuatan bengkok rata-rata sebesar 271,2 N seperti grafik Gambar 9.

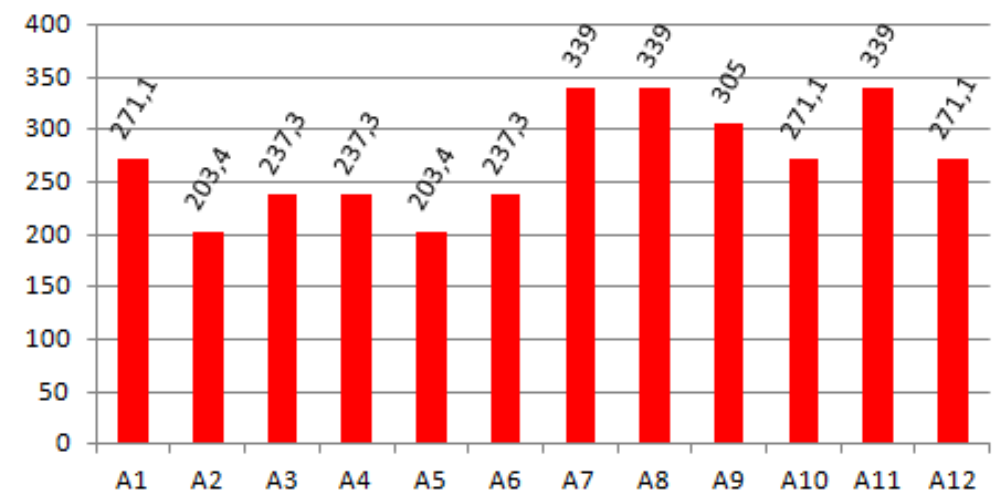

Gambar 9. Hasil pengujian gaya bengkok sampel uji dari bahan PP 
Suyadi dkk./Jurnal Rekayasa Mesin p-ISSN: 1411-6863, e-ISSN: 2540-7678

Vol.15|No.3|220-228|Desember|2020

3.4.2. Momen Bengkok pada hasil Pengujian Kekuatan sampel uji berbahan PP

Momen bengkok dapat diperoleh dari perhitungan gaya bengkok $(\mathrm{F})$ kali radius dalam produk klem $(\mathrm{R}=11 \mathrm{~mm})$, berdasarkan hasil pengujian besarnya momen bengkok masing produk sampel uji berbahan PP dapat dibuat grafik seperti Gambar 10, adapun momen bengkok terendah sebesar 2237 Nmm, momen bengkok tertinggi sebesar 3728,3 $\mathrm{Nmm}$, dan momen bengkok rata-rata sebesar 2982,6 Nmm.

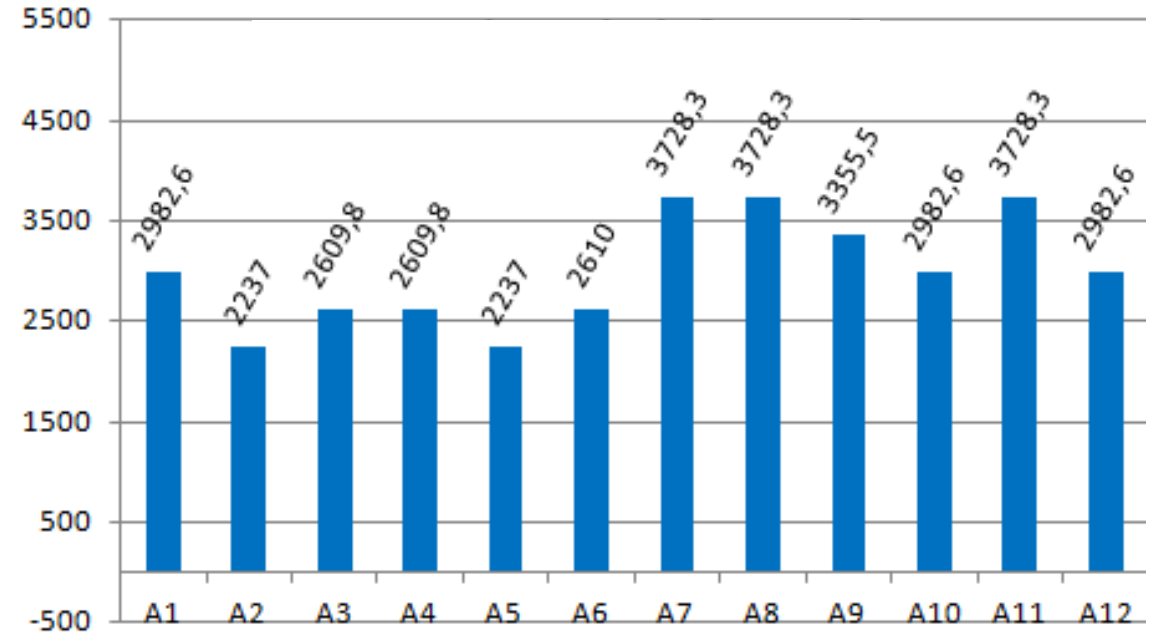

Gambar 10. Hasil Momen bengkok sampel uji dari bahan PP

\subsubsection{Tegangan Bengkok pada hasil Pengujian Kekuatan sampel uji berbahan PP}

Tegangan bengkok pada hasil pengujian tekan diperoleh dengan perhitungan momen bengkok dibagi dengan momen tahanan bengkok, perhitungan tegangan bengkok kedua belas sampel uji berhan PP daur ulang dapat dilihat pada Gambar 11 dimana tegangan bengkok terendah sebesar 3,3 N/mm², yang tertinggi sebesar 6,5 N/mm², dan tegangan bengkok rata-rata sebesar $4,67 \mathrm{~N} / \mathrm{mm}^{2}$.

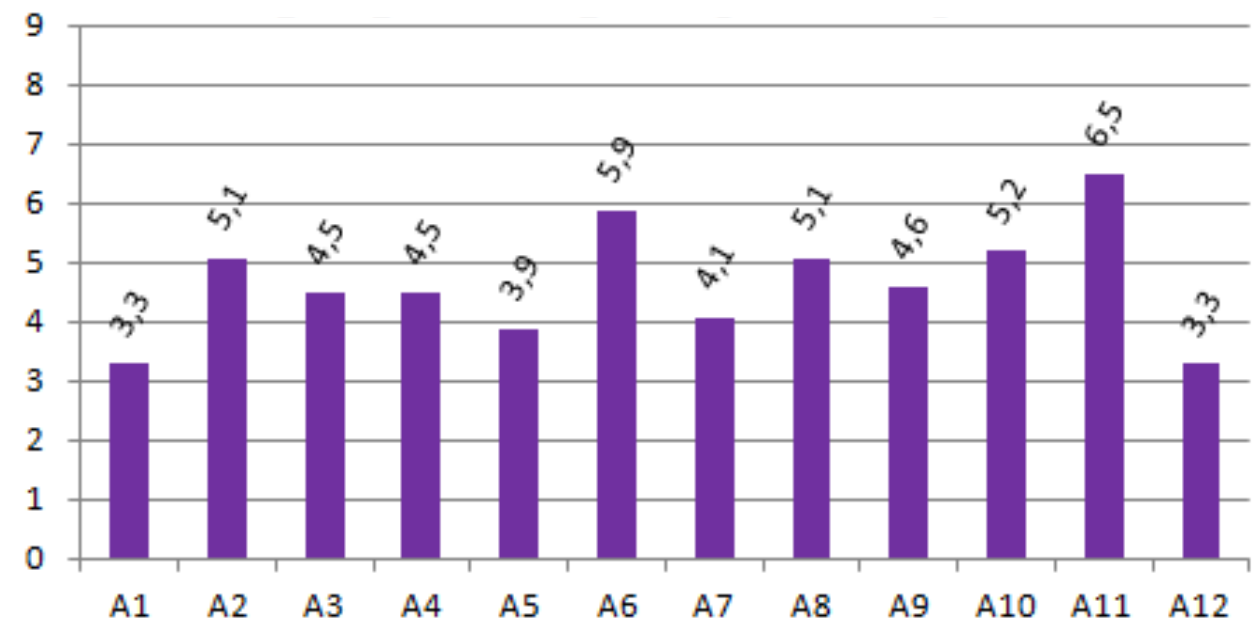

Gambar 11. Hasil tegangan bengkok uji sampel uji dari bahan PP

\subsection{Pembahasan Data Hasil Pengujian Tekan Sampel Uji Terephthalate (PET)}

\subsubsection{Gaya Bengkok pada hasil Pengujian Kekuatan sampel uji berbahan PET}

Berdasarkan hasil pengujian beban bengkok seperti Gambar 12, kedua belas sampel uji berbahan plastik PET daur ulang menunjukkan kekuatan bengkok terendah 203,4 N dan yang tertinggi 271,1 N dan kekuatan bengkok rata-rata sebesar 214,7 N seperti Gambar 12. 
Suyadi dkk./Jurnal Rekayasa Mesin

p-ISSN: 1411-6863, e-ISSN: 2540-7678

Vol.15|No.3|220-228|Desember|2020

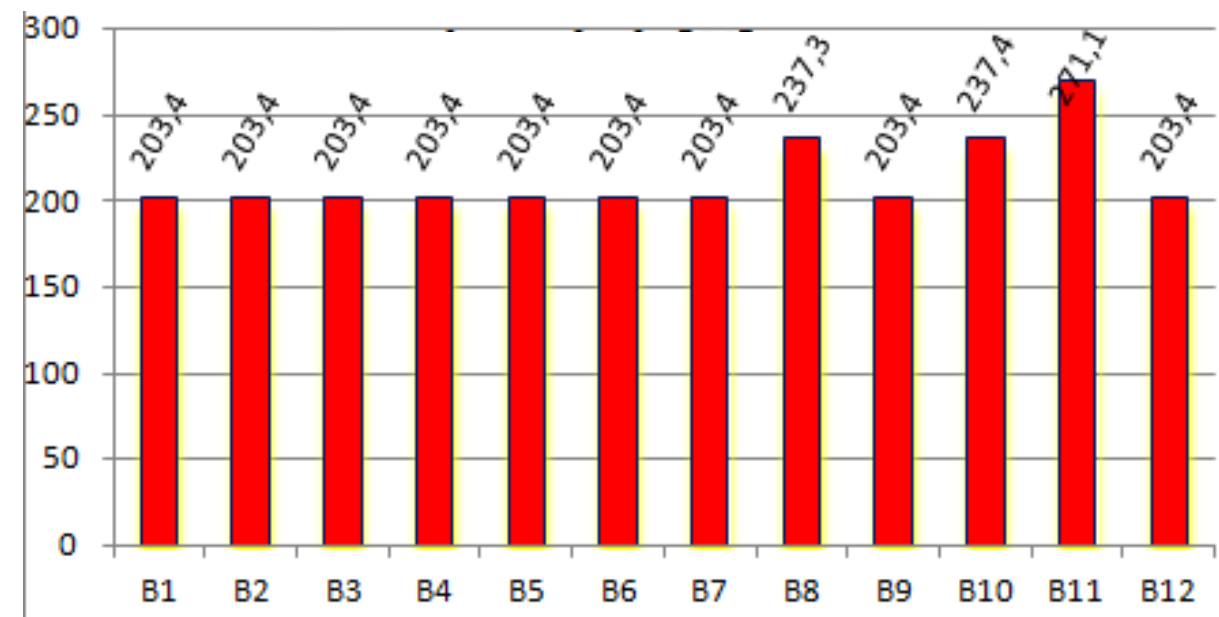

Gambar 12. Hasil pengujian gaya bengkok sampel uji dari bahan PET

\subsubsection{Momen Bengkok pada hasil Pengujian Kekuatan sampel uji berbahan PET}

Momen bengkok dapat diperoleh dari perhitungan gaya bengkok $(\mathrm{F})$ kali radius dalam klem $(\mathrm{R}=11 \mathrm{~mm})$, berdasarkan hasil pengujian besarnya momen bengkok masing masing sampel uji berbahan PP dapat dibuat grafik seperti Gambar 13, adapun momen bengkok terendah sebesar 2237 Nmm, momen bengkok tertinggi sebesar 2983 Nmm, dan momen bengkok rata-rata sebesar 2361,33 Nmm.

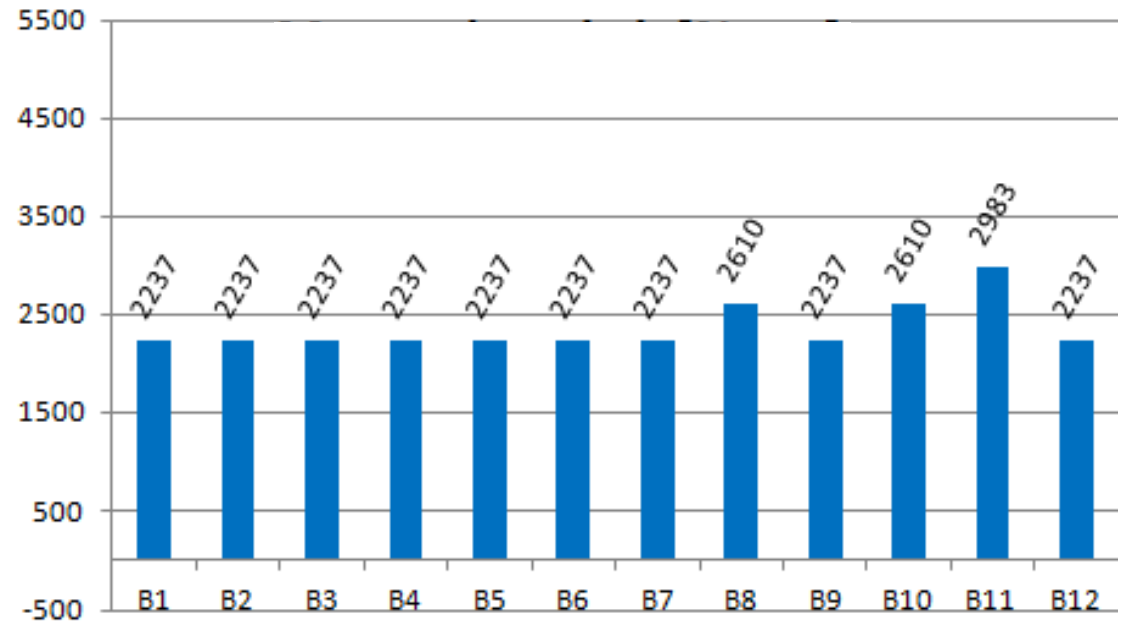

Gambar 13. Hasil pengujian momen bengkok sampel uji dari bahan PET

\subsubsection{Tegangan Bengkok pada hasil Pengujian Kekuatan sampel uji berbahan PET}

Tegangan bengkok pada hasil pengujian tekan diperoleh dengan perhitungan momen bengkok dibagi dengan momen tahanan bengkok, perhitungan tegangan bengkok keduabelas sampel uji berbahan PET daur ulang dapat dilihat pada Gambar 14 dimana tegangan bengkok terendah sebesar 3,9 N/mm², yang tertinggi sebesar 5,9 N/mm², dan tegangan bengkok rata-rata sebesar $4,325 \mathrm{~N} / \mathrm{mm}^{2}$. 
Suyadi dkk./Jurnal Rekayasa Mesin

p-ISSN: 1411-6863, e-ISSN: 2540-7678

Vol.15|No.3|220-228|Desember|2020

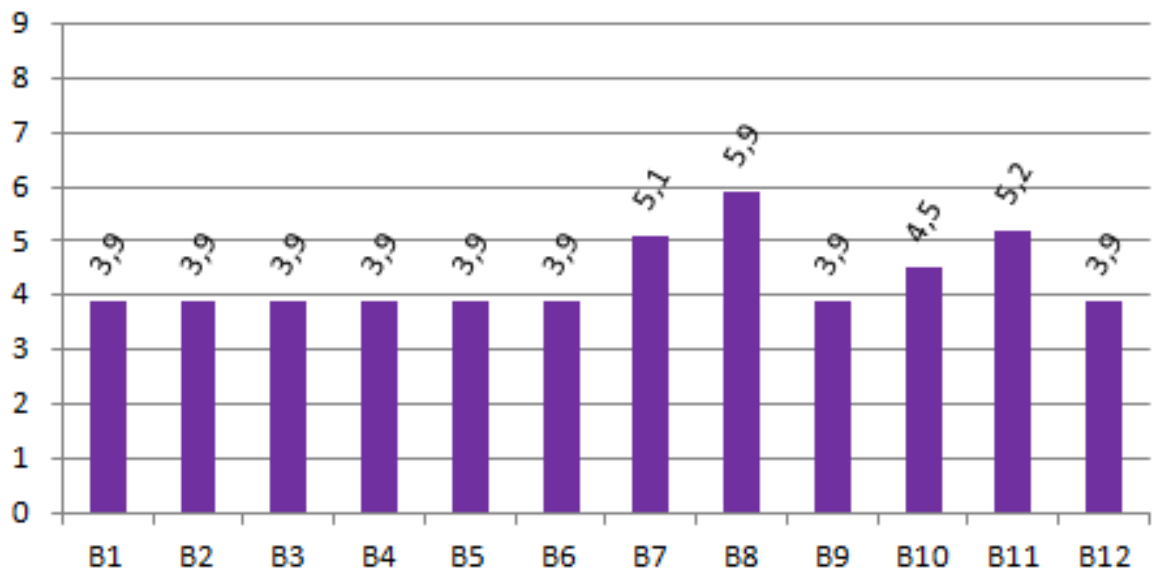

Gambar 14. Hasil pengujian tegangan bengkok sampel uji dari bahan PET

\subsection{Rekapitulasi Hasil Penelitian}

Bahan limbah/sampah plastik dari bahan PP dan PET dapat diolah menjadi suatu produk Klem penjepit pipa paralon karena kekuatannya masih mampu memegang pipa paralon tersebut, berdasarkan penelitian ini untuk hasil daur ulang plastik PP mempunyai tegangan bengkok $4,67 \mathrm{~N} / \mathrm{mm}^{2}$ dan untuk tegangan bengkok hasil plastik daur ulang PET sebesar 4,3 N/mm² bila dibandingkan dengan hasil uji tarik plastik daur ulang PP mempunyai tegangan tarik 12,2 $\mathrm{N} / \mathrm{mm}^{2}$ dan tegangan tarik dari plastik PET daur ulang sebesar 23,4 N/mm² [8].

Walaupun pada penelitian ini menghasilkan tegangan bengkok PP lebih tinggi dari tegangan bengkok PET namun perbedaannya tidak begitu signifikan. Ada beberapa hasil kekuatan bengkok penelitian ini yang menghasilkan ketidak konsistennya hasilnya karena pemberian gaya compression saat mencetak tidak terukur dengan teliti karena gaya compression menggunakan dongkrak hidrolik (hidraulic jack) tanpa dilengkapi alat ukur tekanan.

\section{Kesimpulan}

Dari hasil pengujian didapatkan produk klem plastik pemegang pipa paralon 1/2 inchi terbuat dari daur ulang Polypropylene (PP) menghasilkan kekuatan/tegangan bengkok sebesar $\sigma_{b}=4,67 \mathrm{~N} / \mathrm{mm}^{2}$. Produk klem plastik pemegang pipa paralon 1/2 inchi yang terbuat dari daur ulang Polyethylene Terephthalate (PET) menghasilkan kekuatan/tegangan bengkok sebesar $\sigma_{b}=4,325 \mathrm{~N} / \mathrm{mm}$. Cetakan yang terbuat dari baja karbon mampu menerima panas sampai $250^{\circ} \mathrm{C}$ dan mampu menahan gaya tekan $5000 \mathrm{~N}$. Cetakan terbagi dua yaitu cetakan atas dan cetakan bawah masing-masing mempunyai ukuran tebal $18 \mathrm{~mm}$ x $60 \mathrm{~mm}$ x $100 \mathrm{~mm}$ dan kalau cetakan atas dan bawah ditangkupkan menjadi ukuran $18 \mathrm{~mm}$ x $90 \mathrm{~mm}$ x $100 \mathrm{~mm}$.

\section{Daftar Pustaka}

[1] Carli, dkk, 2006, Penerapan Mesin Perajang Limbah Plastik Botol Minuman Untuk Meningkatkan Produktivitas Dan Kualitas Produk Pada Ukm Pengolah Limbah Plastik Menjadi Siap Olah, Prgram TTG, Depdiknas Jateng.

[2] http://en.wikipedia.org/wiki/Polyethylene_terephthalate, diakses 24-12-2020

[3] -------- 2003, Hasil Studi Eksplorasi Pada Industri Pengolah Limbah Sampah Plastik di Semarang, Ungaran dan Kendal.

[4] Meriam, JL , 1993, Mekanika Teknik Dinamika, Erlangga, Jakarta.

[5] Suyadi, dkk, 2007, Pembuatan Alat Uji Tarik Sampel Plastik Sistem Pneumatik Dengan Memanfaatkan MikrokontrolerUntuk Diversivikasi Pengujian Destruktif Non Metal, Penelitian Dosen Muda, Dikti Jakarta. 
Suyadi dkk./Jurnal Rekayasa Mesin

p-ISSN: 1411-6863, e-ISSN: 2540-7678

Vol.15|No.3|220-228|Desember|2020

[6] Suyadi, dkk, 2009, Kaji Eksperimen Kekuatan Tarik Produk-produk Berbahan Plastik Daur ulang, Penelitian Hibah Bersaing, Dikti Jakarta.

[7] Taufiq Rochim, 1995, Teori Dan Teknologi Prsoses Pemesinan, Bandung, ITB.

[8] Suyadi, 2010, Kaji Eksperimental Kekuatan Tarik Produk-produk Berbahan Plastik Daur Ulang, Prosiding SNST Unwahas D.104-D111. 